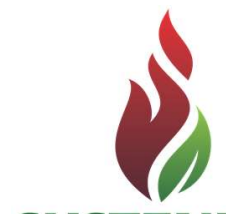

SUSTENERE

Publishing Corporation
ZRBADM

Journals Homepage:

www.sustenere.co/journals

\section{ESTRUTURA DE CAPITAL DAS EMPRESAS DO BRASIL E CHINA MEDIANTE A CRISE FINANCEIRA MUNDIAL}

\section{RESUMO}

Desde a década de 50 , diversas pesquisas buscam compreender as variáveis clássicas que determinam a estrutura de capital das empresas. Mas apenas recentemente encontram-se evidências da influência de outros aspectos, tais como as variáveis institucionais e macroeconômicas, que também expliquem essa estrutura de capital. Nesse contexto, os períodos de recessão e crise financeira vêm se tornando relevantes para novas pesquisas. Este trabalho teve como objetivo principal analisar as estruturas de capital das empresas do Brasil e da China, mediante a crise financeira mundial iniciada nos Estados Unidos em 2007. Esta é uma pesquisa de caráter descritivo e explicativo, com o uso da abordagem quantitativa. Têm-se como população da pesquisa as empresas listadas nas Bolsas de Valores dos dois países analisados, relação da qual foram excluídas as empresas do setor financeiro, que apresentavam patrimônio líquido negativo e não dispunham de informações suficientes na base de dados Compustat no período de 2002 a 2011, formando-se assim a amostra do estudo. Para a análise dos dados foi utilizado o modelo de painel desbalanceado com efeitos fixos. Os resultados expõem uma relação inversa entre crise subprime e o endividamento de todas as empresas do estudo, além de expor a importância dos fatores macroeconômicos na definição da estrutura de capital, assim como das relações que comprovam o previsto pelas teorias de Tradeoff e Pecking Order. Assim, em momentos de crise financeira, há um indicativo para que as empresas ajustem a estrutura de capital.

PALAVRAS-CHAVES: Estrutura de capital; Tradeoff Theory; Pecking Order Theory; Crise financeira.

\section{CAPITAL STRUCTURE OF BRAZIL AND CHINA COMPANIES BY GLOBAL FINANCIAL CRISIS}

\section{ABSTRACT}

Since the 50s, several studies seek to understand classical variables that determine the capital structure of companies. But only recently are evidence of the influence of other aspects, such as institutional and macroeconomic variables, which also explain the capital structure. In this context, periods of recession and financial crisis are becoming relevant to new research. This study aimed to analyze the capital structures of the companies in Brazil and China by the global financial crisis started in the USA in 2007. This is a descriptive and explanatory research study, using the quantitative approach. The population research companies is listed on stock exchanges of the two countries analyzed, except companies of the financial sector and companies had negative equity and they did not have sufficient information in Compustat database from 2002 to 2011, thereby forming the study sample. To analyze the data we used the model of unbalanced panel with fixed effects. The results exhibit an inverse relationship between subprime crisis and the indebtness of the companies, in addition to exposing the importance of macroeconomic factors in the definition of capital structure, as well as relations that show the predicted by Tradeoff and Pecking Order theories. Thus, in times of financial crisis, there is an indication for companies to adjust the capital structure.

KEYWORDS: Capital Structure; Tradeoff Theory; Pecking Order Theory; Financial Crisis.
Revista Brasileira de

Administração Científica,

Aquidabã, v.6, n.1, Jan, Fev, Mar, Abr, Mai, Jun 2014.

ISSN 2179-684X

SECTION: Articles

TOPIC: Finanças e Contabilidade

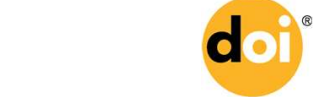

DOI: 10.6008/SPC2179-684X.2015.001.0006

Marcela Stéphanie C. de Vasconcelos Universidade Federal de Pernambuco, Brasil http://lattes.cnpq.br/76642144466877619 adm.marcelavasconcelos@gmail.com

Joséte Florencio dos Santos

Universidade Federal de Pernambuco, Brasil http://lattes.cnpq.br/5657418279526928 ifs@ufpe.br

Moisés Araújo Almeida

Universidade Federal de Sergipe, Brasil http://lattes.cnpq.br/2418237727476637 moisesaraujoalmeida@yahoo.com.br

Edilson dos Santos Silva

Universidade Federal de Pernambuco, Brasil http://lattes.cnpq.br/9314379911392966 santosedilson@hotmail.com

Received: 18/03/2015

Approved: 14/10/2015

Reviewed anonymously in the process of blind peer

Referencing this:

VASCONCELOS, M. S. C.; SANTOS, J. F.; ALMEIDA, M. A.; SILVA, E. S.. Estrutura de capital das empresas do Brasil e China mediante a crise financeira mundial. Revista Brasileira de Administração Científica, Aquidabã, v.6, n.1, p.92-113, 2015. DOl:

http://dx.doi.org/10.6008/SPC2179$684 X .2015 .001 .000$ 


\section{INTRODUÇÃO}

O tema estrutura de capital tem sido discutido na literatura financeira há mais de meio século. Modigliani e Miller (1958) publicaram um artigo pioneiro sobre o tema, que se apoia no pressuposto de existência de um mercado de capital perfeito, sem assimetria de informações, impostos, taxas de juros dos financiamentos e custos de transação, com acesso limitado ao crédito. Eles defendiam que a estrutura de capital seria irrelevante para maximizar o valor da empresa. Num trabalho posterior, Modigliani e Miller (1963) fizeram algumas considerações acerca de suas proposições iniciais, principalmente em relação aos aspectos sobre tributação. Eles reconheceram os benefícios fiscais com o aumento da alavancagem financeira. As empresas deveriam escolher uma estrutura com predomínio quase total de capital de terceiros em detrimento do uso de capital próprio. Desta forma, a estrutura de capital ganha importância para a valoração da empresa.

Após os trabalhos de Modigliani e Miller houve um desenvolvimento da teoria de estrutura de capital e as duas teorias que mais se destacam nos estudos sobre esse tema são Tradeoff e Pecking Order. A teoria de Tradeoff, desenvolvida por Myers (1984), propõe uma estrutura de capital ótima para obter a maximização do valor da empresa, ou seja, busca-se um equilíbrio do endividamento entre recursos de capital próprio e de terceiros, ao ponderar os custos de dificuldades financeiras e os benefícios fiscais. Por sua vez, a teoria de Pecking Order, proposta por Myers (1984) e Myers e Majluf (1984), sustenta que há uma hierarquia na captação de recursos por parte das empresas, as quais preferem recursos internos (lucros acumulados) aos externos (aquisição de dívida ou emissão de novas ações), visto que esta teoria considera a existência de assimetria de informações no mercado de capitais.

Com base nestas teorias, as pesquisas acadêmicas vêm explorando o tema na tentativa de encontrar variáveis determinantes do endividamento das empresas e explicar o comportamento de financiamento corporativo na tentativa de maximizar seu valor. Diversos fatores determinantes da estrutura de capital foram estabelecidos pelos estudiosos da área, tais como rentabilidade, risco do negócio, tamanho da empresa, oportunidade de crescimento e tangibilidade dos ativos. Contudo, segundo Bastos et al. (2009) e Lima et al. (2011), além desses fatores internos, as empresas tendem a alterar seu nível de endividamento de acordo com as mudanças ocorridas no ambiente externo da organização (ambiente macroeconômico), a exemplo da taxa de juros praticada no mercado, taxa de crescimento do PIB, taxa de inflação e estabilidade econômica. Assim, as empresas podem ficar mais suscetíveis às alterações em âmbito global, como nas crises mundiais. Desse modo, a crise financeira de 2007 ganha importância para intermediar períodos diferentes e tentar compreender o comportamento da estrutura de capital (forma de financiamento) das empresas em momentos de estresse.

A crise financeira de 2007 ou crise subprime, originária dos Estados Unidos, teve como causa a decisão do governo americano de diminuir as taxas de juros e impostos para proporcionar 
o aquecimento de sua economia. Dessa forma, o consumo, em destaque o imobiliário, foi estimulado pela grande oferta de crédito a baixo custo e a subestimação do risco de perda por parte das instituições financeiras ao fornecer concessões de empréstimos às pessoas sem condições de quitar suas dívidas. Desta maneira, o governo teve que tomar medidas restritivas para conter a inflação originária da valorização dos preços no mercado imobiliário, aumentando, assim, as taxas de juros. Consequentemente, o nível de inadimplências aumentou e as instituições financeiras tiveram problemas de liquidez, o que gerou a diminuição da oferta de crédito e maior rigor na concessão de financiamentos e na análise de risco e retorno. Embora a crise tenha iniciado nos Estados Unidos, a globalização facilitou sua rápida disseminação mundial, o que gerou uma profunda recessão econômica em diversas regiões (SILVA, 2010).

Os países emergentes também foram impactados pela crise. Entre esses países, dois se destacam na economia mundial atualmente e são tratados no presente artigo. O primeiro deles é a China, um país em acelerado desenvolvimento econômico com crescimento anual do PIB de cerca de 10\%, atingindo US\$ 8.227 trilhões de dólares em 2012. O segundo é o Brasil, um dos maiores países em desenvolvimento da América Latina, que detém um dos maiores PIB do mundo com US\$ 2.223 trilhões de dólares em 2012, mesmo com a queda da taxa de crescimento de seu PIB em 2012 (BANCO MUNDIAL, 2013). Além desse destaque econômico, esses países têm grande relevância nessa pesquisa devido ao estreitamento das relações comerciais entre eles (BERTONHA, 2013; CUNHA et al., 2011). Diante do exposto, este artigo tem por objetivo identificar de que forma a crise financeira mundial impactou nas decisões de estrutura de capital das empresas de capital aberto do Brasil e da China.

\section{REVISÃO TEÓRICA}

O tema estrutura de capital alcançou maior destaque a partir de Modigliani e Miller (1958), doravante chamados de M\&M, ao contrapor a ideia tradicionalista de Durand (1952), que defendia a maximização do valor da empresa por meio da combinação ótima do capital próprio e de terceiros. Então, sob um cenário ideal, M\&M (1958) assumem a não influência da estrutura de capital no valor da empresa, levando a surgir críticas à sua tese por ser considerada irreal a existência de um mercado perfeito. Assim, as Finanças Corporativas ganharam diversas teorias sobre estrutura de capital utilizando os ensinamentos e as falhas dos estudos de autoria de M\&M (1958). A seguir são destacadas duas dessas teorias.

\section{Teoria de Tradeoff}

Uma das principais teorias desenvolvidas após os estudos de M\&M foi à teoria de Tradeoff. De acordo com Myers (1984), esta teoria considera que os benefícios fiscais e os custos de dificuldades financeiras devem ser analisados à medida que a empresa aumenta sua dívida. $O$ 
maior endividamento aumentará os benefícios para a empresa, porém ao ultrapassar o chamado ponto ótimo (ponto de endividamento em que a empresa maximizará seu valor) os custos de dívida se sobressaem aos benefícios fiscais, resultando em um efeito contrário ao esperado. Dessa forma, essa teoria assume que as empresas devem buscar uma estrutura ótima de capital através da minimização dos custos e maximização dos benefícios fiscais.

Entre os benefícios do endividamento, o tributário ou fiscal é considerado o de maior relevância desde os estudos de M\&M (1963), quando os autores observaram que ao alavancar a empresa, os impostos a serem pagos sofrem deduções referentes às despesas com juros. Já entre os custos da dívida, o custo de falência aparece como destaque, pois relaciona o endividamento da empresa com a possibilidade da mesma quebrar, ou seja, o aumento de dívida aumenta as chances de falência da mesma (NAKAMURA et al. 2007).

\section{Teoria de Pecking Order}

A segunda é a teoria de Pecking Order, criada por Myers (1984) e Myers e Majluf (1984), que refuta a concepção de nível ótimo de capital a partir do princípio de que o financiamento de uma empresa é feito de forma preferencial e hierárquica ao decidir por apenas uma forma de financiamento. Conforme Myers (1984), a preferência de financiamento das empresas se dá, primeiramente, com seus recursos próprios até o momento em que esse capital seja capaz de financiar seus investimentos. Porém, quando isso não é mais possível, ou seja, as obrigações de pagamento a serem assumidas ultrapassam a capacidade de quitação da empresa, os recursos externos tornam-se necessários. Portanto, em ordem decrescente de preferência, espera-se que o fluxo de caixa seja o mais utilizado, seguido pela emissão de novas dívidas quando ocorre o déficit financeiro e, por último, a emissão de novas ações.

Contudo, essas formas de financiamento podem ser interpretadas de forma negativa por mercado e acionistas, visto que a imagem e o valor da empresa tendem a ser influenciados pela assimetria de informação. Essa, por sua vez, considera que as partes envolvidas em uma transação são diferentemente informadas, o que leva determinados agentes a obter vantagem informacional por possuir informações privilegiadas em relação aos outros (IQUIAPAZA et al., 2008). Dessa forma, torna-se fundamental a fiscalização e regulação dessas negociações, pois esse desequilíbrio propicia o aumento da desconfiança dos informacionalmente desfavorecidos, assim como do custo de transação. A partir desse princípio, Myers e Majluf (1984) identificaram a relevância de relacionar a assimetria de informações com as decisões de estrutura de capital.

\section{Determinantes da Estrutura de Capital}

Apesar de estrutura de capital ser um dos temas mais complexos das finanças corporativas, devido à ausência de padrões teóricos a serem seguidos, assim como a existência 
de diversos fatores determinantes da estrutura de capital que influenciam de forma distinta as tomadas de decisão das empresas, foram vários os autores que testaram empiricamente as diversas relações dos determinantes com o grau de endividamento, fundamental para identificar os motivos pelos quais as empresas realizam financiamentos. Além disso, essas pesquisas permitiram verificar a validade das teorias clássicas e modernas no que diz respeito à estrutura de capital. Contudo, os resultados desses estudos empíricos são divergentes entre si, consequentemente aumenta a dificuldade de encontrar padrões referentes à área estudada.

\section{Rentabilidade ou Lucratividade}

Segundo a teoria de Pecking Order, a variável rentabilidade tem relação inversa com a dívida da empresa, ou seja, quanto mais rentável for a empresa menor deverá ser o seu nível de endividamento. A explicação é que a empresa sob a posse de mais capital próprio irá usá-lo como fonte principal de investimento no negócio, caso os lucros não sejam distribuídos aos acionistas. Diversos são os trabalhos empíricos que confirmaram esta relação (VALLE, 2008; FUTEMA et al., 2009; VALLE \& ALBANEZ, 2012; CORREA et al., 2013; FORTE et al., 2013). Por outro lado, a teoria de Tradeoff assume uma relação positiva da lucratividade com o endividamento, ao levar em consideração o benefício de maior dedução de juros sobre o imposto resultante de maiores lucros, quando esses não forem distribuídos. Essa relação é mais escassa nos trabalhos empíricos, poucos são os autores como Antoniou et al. (2008) que a identificaram.

\section{Risco do Negócio}

O fator risco é fundamental aos tomadores de decisão e torna-se mais relevante na presença de forças que atingem vários ativos em diversas intensidades, como o risco sistemático da crise financeira, o qual é cenário deste estudo. Assim, quanto maior o risco de negócio maior será a exposição da empresa às situações de falência. Quanto menos arriscada ela for, maior a probabilidade dela conseguir captar recursos de terceiros. Dessa forma, existe uma relação inversa entre o risco do negócio e o grau de financiamento com dívidas, de acordo com ambas as teorias (NAKAMURA et al., 2007; CORREA et al., 2013). Os resultados empíricos confirmam esta relação negativa prevista pelas teorias (FAVATO \& ROGERS, 2008; VALLE \& ALBANEZ, 2012).

\section{Tamanho da Empresa}

A variável tamanho tem relação positiva com o nível de endividamento como preconizam as teorias de Tradeoff e Pecking Order, devido ao fato de que as empresas de maior porte tendem a ser mais diversificadas e a ter menor risco de negócio, o que as torna capazes de reduzir os custos envolvidos na contratação de dívida externa (NAKAMURA et al., 2007). Corroborando com 
as previsões teóricas, os trabalhos empíricos confirmam esta relação positiva (RAJAN \& ZINGALES, 1995; BARROS \& SILVEIRA, 2008; MEDEIROS \& DAHER, 2008; ESPINOSA et al., 2012; FORTE et al., 2013).

Contudo a teoria de Pecking Order tem características ambíguas quanto a esta variável quando também considera a relação negativa entre as variáveis ao identificar que as empresas maiores têm menor assimetria de informações entre os insiders e o mercado de capitais. Isso as leva a preferir a emissão de títulos mais sensíveis à informação como é o caso das ações em detrimento das dívidas (RAJAN \& ZINGALES, 1995).

\section{Tangibilidade dos Ativos}

Os ativos tangíveis podem ser utilizados como garantias nas operações financeiras, dando aos credores mais confiança para fazer o financiamento. Isso reduz os custos financeiros e de agência e incentiva o aumento da alavancagem das empresas (BASTOS et al., 2009; CORREA et al., 2013). A teoria defende a existência de um relacionamento positivo entre o nível de tangibilidade dos ativos e o endividamento. Corroborando com a teoria de Tradeoff, essa relação positiva foi observada por Barros e Silveira (2008), Albanez e Valle (2009), Tristão e Dutra (2012) e Valle e Albanez (2012), dentre outros. Com base na teoria de Pecking Order é esperada uma relação negativa, haja vista que as empresas com menos ativos tangíveis são mais propensas a ter maior nível de assimetria de informações, o que leva a empresa a captar mais recursos externos (BASTOS et al. 2009). Esse sinal negativo foi encontrado por autores como Favato e Rogers (2008), Medeiros e Daher (2008), Kayo e Kimura (2011) e Correa et al. (2013).

\section{Oportunidade de Crescimento}

A teoria de Tradeoff também prevê que o endividamento se relaciona negativamente com o crescimento. Isso se justifica pelo fato de que o crescimento de uma empresa poderá ser comprometido caso ela tenha adquirido altos níveis de dívida. Da mesma forma, a teoria de Pecking Order também considera um relacionamento negativo ao defender que as empresas com alta perspectiva de crescimento, para não comprometer sua capacidade de crédito, buscam reduzir seu nível de endividamento. Essa relação inversa foi encontrada nos estudos de Huang e Song (2006), Nakamura et al. (2007), Valle (2008), Iquiapaza et al. (2008), Bastos et al. (2009), Espinosa et al. (2012). No entanto, a teoria de Pecking Order também assume a possibilidade de uma relação positiva entre crescimento e endividamento, pois quando uma empresa necessita de investimentos para expandir é comum acumular mais dívida (FAVATO \& ROGERS, 2008; BASTOS et al., 2009). Essa relação positiva pode ser observada no trabalho de Forte et al. (2013). 


\section{Taxa de Crescimento do PIB}

O crescimento do PIB como fator macroeconômico e específico do país também exerce influência sobre a estrutura de capital das empresas. Evidências empíricas são encontradas no estudo de Terra (2007) e no de Bastos et al. (2009), que verificaram uma relação negativa entre o PIB e o endividamento total ao perceber a diminuição de captação de dívidas, por parte das empresas, quando há crescimento econômico. Para os últimos autores, o PIB foi a variável macroeconômica mais relevante estatisticamente no seu estudo. Isso ocorre devido ao aumento de recursos internos para o próprio financiamento das empresas, o que faz com que o endividamento deixe de ser atrativo. Dessa forma, esse resultado corrobora com a teoria de Pecking Order (MYERS, 1984). Além disso, "os fatores macroeconômicos e institucionais não podem mais ser desconsiderados, pois são fatores que ajudam a explicar o comportamento das empresas, embora ainda haja muito que se pesquisar nesse campo" (BASTOS et al., 2009, p.76), aumentado assim a relevância do PIB neste estudo.

\section{Taxa de Inflação}

Por fim, embora a variável inflação seja pouco tratada nos estudos de estrutura de capital, sabe-se que ela pode influenciar de forma positiva a alavancagem, como pressupõe a teoria de Tradeoff. Quanto mais alta é a inflação sobre as taxas de juros, maiores serão os montantes de dívidas emitidos (FRANK \& GOYAL, 2007). Para Lima et al. (2011), as empresas tendem a aumentar seus níveis de endividamento em períodos de controle inflacionário.

\section{Crise Financeira}

Muitos são os estudos que analisam os efeitos da crise financeira nas decisões de financiamento das empresas nas empresas de capital aberto. Porém, esses estudos ainda são voltados para os mercados mais desenvolvidos (AKBAR et al., 2013). Neste contexto, torna-se relevante verificar a influência de períodos de recessão e crise nas tomadas de decisões de financiamento das empresas de capital aberto de países em desenvolvimento, como Brasil e China, para verificar se as empresas se veem obrigadas a recorrer a fontes externas de capital nos momentos em que os lucros diminuem de maneira anormal, medida que aumentaria sua alavancagem.

\section{METODOLOGIA}

A fim de compreender o problema elencado, a pesquisa qualifica-se a partir dos objetivos e procedimentos técnicos utilizados. Quanto aos objetivos, este estudo tem caráter descritivo e 
explicativo. Para ser considerada uma pesquisa descritiva, devem-se descrever e detalhar as características da população estudada ou relacionar variáveis em busca de associações. Por sua vez, a pesquisa explicativa utiliza esta descrição para identificar os fatores determinantes e a razão da problemática (GIL, 2010). Já para analisar e mensurar os dados, esta pesquisa utiliza a abordagem quantitativa, ao envolver métodos estatísticos para relacionar a teoria com os dados práticos e estabelecer inferências (GIL, 2010).

\section{População e Amostra}

A população da pesquisa foi constituída por empresas brasileiras e chinesas de capital aberto listadas na BM\&FBOVESPA e na Shanghai Stock Exchange (SSE), respectivamente, no período de 2002 a 2011, constantes na base de dados Compustat. No entanto, foram excluídas da amostra as empresas que apresentavam patrimônio líquido negativo, as que estavam inseridas no setor financeiro - por serem um grupo particular de empresas, com características distintas das demais - e as que não dispunham de informações suficientes. Após esse filtro, obteve-se a amostra final da pesquisa, a qual variou de forma crescente ao longo do período analisado. De acordo com essas informações, observa-se a composição do universo de pesquisa e sua amostra por ano e por país estudado na Tabela 1:

Tabela 1: Número de empresas do universo e da amostra da pesquisa em cada ano.

\begin{tabular}{|c|c|c|c|c|}
\hline \multirow{2}{*}{ Ano } & \multicolumn{2}{|l|}{ Brasil } & \multicolumn{2}{|l|}{ China } \\
\hline & Universo & Amostra & Universo & Amostra \\
\hline 2002 & 272 & 73 & 3460 & 312 \\
\hline 2003 & 263 & 91 & 3345 & 370 \\
\hline 2004 & 246 & 91 & 3234 & 829 \\
\hline 2005 & 242 & 93 & 3193 & 1222 \\
\hline 2006 & 237 & 123 & 3069 & 1292 \\
\hline 2007 & 229 & 133 & 2720 & 1376 \\
\hline 2008 & 226 & 136 & 2456 & 1472 \\
\hline 2009 & 224 & 178 & 2345 & 1569 \\
\hline 2010 & 220 & 189 & 2316 & 1912 \\
\hline 2011 & 224 & 195 & 2316 & 2185 \\
\hline
\end{tabular}

\section{Coleta e Tratamento dos Dados}

Os dados contábeis utilizados são públicos e oriundos de balanços patrimoniais e das demonstrações do resultado do exercício das empresas no período de 2002 a 2011, que podem ser encontrados na base de dados Compustat. Por sua vez, os dados macroeconômicos, a taxa de crescimento do PIB (\% anual) e a taxa de inflação foram retirados do site do International Finance Corporation (Banco Mundial). Com o auxílio do Microsoft Excel foi possível, inicialmente, tratar os dados por meio da elaboração de planilhas, histogramas e gráficos. Para as questões econométricas, foi utilizado o software Stata 12. 


\section{Definição Operacional das Variáveis}

As variáveis foram operacionalizadas conforme descrito a seguir, tendo como base a discussão apresentada no referencial teórico.

\section{Variável Dependente}

A variável dependente usada neste estudo para mensurar a estrutura de capital das empresas é o endividamento de longo prazo. Alternativamente, serão utilizados o endividamento total e o endividamento de curto prazo. No Quadro 1, a seguir, são apresentadas as fórmulas usadas para calcular cada uma destas variáveis.

Quadro 1: Variáveis dependentes.

\begin{tabular}{|l|l|l|}
\hline Variável Dependente & Sigla & Fórmula \\
\hline Endividamento Total & ET & Passivo Total / Ativo Total \\
\hline Endividamento de Curto Prazo & ECP & Passivo Circulante / Ativo Total \\
\hline Endividamento de Longo Prazo & ELP & Passivo Não Circulante / Ativo Total \\
\hline
\end{tabular}

\section{Variáveis de Controle}

Os fatores determinantes da estrutura de capital das empresas são definidos como variáveis de controle. No Quadro 2 se encontram, de forma resumida, as fórmulas utilizadas para calculá-las. Utilizou-se ainda a variável dummy crise (CRISE) que assume o valor 0 para o período anterior à crise (2002 a 2006) e o valor 1 no período seguinte (2007-2011), a fim de verificar o impacto da crise financeira mundial no endividamento.

Quadro 2: Variáveis de controle

\begin{tabular}{|l|l|l|l|}
\hline Descrição & Sigla & Operacionalização & Autores \\
\hline Tangibilidade & TANG & Ativo Imobilizado / Total de Ativos & $\begin{array}{l}\text { Favato e Rogers (2008) e Albanez e } \\
\text { Valle (2009) }\end{array}$ \\
\hline Retorno sobre o Ativo & ROA & EBIT / Total de Ativos & $\begin{array}{l}\text { Iquiapaza et al. (2008), Bastos et al. } \\
\text { (2009), Ceretta et. al. (2009) e David } \\
\text { et al. (2009) }\end{array}$ \\
\hline $\begin{array}{l}\text { Oportunidade de } \\
\text { Crescimento }\end{array}$ & CRESC & $\begin{array}{l}\text { (Ativo Total - Patrimônio Líquido + Valor de } \\
\text { Mercado das Ações) / Ativo Total }\end{array}$ & Jong, Kabir e Nguyen (2008) \\
\hline Tamanho da Empresa & TAM & Logaritmo do Total de Ativos & $\begin{array}{l}\text { Titman e Wessels (1988), David et } \\
\text { al. (2009) e Albanez e Valle (2009) }\end{array}$ \\
\hline Risco do Negócio & RISC & Desvio Padrão do EBIT / Total de Ativos & Correa et al. (2013) \\
\hline $\begin{array}{l}\text { Taxa de crescimento do } \\
\text { PIB }\end{array}$ & TPIB & Taxa anual do crescimento do PIB & $\begin{array}{l}\text { site do International Finance } \\
\text { Corporation (Banco Mundial) }\end{array}$ \\
\hline Taxa de inflação & TINF & Taxa anual de inflação & $\begin{array}{l}\text { site do International Finance } \\
\text { Corporation (Banco Mundial) }\end{array}$ \\
\hline Crise financeira & CRISE & $\begin{array}{l}\text { Variável dummy que captura os efeitos da } \\
\text { crise }\end{array}$ & Huang et al. (2014) \\
\hline
\end{tabular}

As relações de todas essas variáveis com o endividamento, encontradas pelos autores estudados sob a ótica da teoria de Tradeoff e Pecking Order, estão no Quadro 3. 
Quadro 3: Relação esperada para as variáveis de controle da estrutura de capital segundo as teorias de Tradeoff e Pecking Order.

\begin{tabular}{|c|c|c|c|c|}
\hline \multirow{2}{*}{ Variável } & \multicolumn{2}{|c|}{ Teoria de Tradeoff } & \multicolumn{2}{|c|}{ Teoria de Pecking Order } \\
\hline & Sinal & Evidência empírica & Sinal & Evidência empírica \\
\hline Tangibilidade & + & $\begin{array}{l}\text { Barros e Silveira (2008), Albanez e Valle } \\
\text { (2009), Tristão e Dutra (2012), Espinosa et al. } \\
\text { (2012), Valle e Albanez (2012) }\end{array}$ & - & $\begin{array}{l}\text { Favato e Rogers (2008), Medeiros e } \\
\text { Daher (2008), Kayo e Kimura (2011), } \\
\text { Correa et al. (2013) }\end{array}$ \\
\hline Retorno do Ativo & + & Antoniou, Guney e Paudyal (2008) & - & $\begin{array}{l}\text { Valle (2008), Futema et al. (2009), } \\
\text { Valle e Albanez (2012), Correa et al. } \\
\text { (2013), Forte et al. (2013) }\end{array}$ \\
\hline $\begin{array}{l}\text { Oportunidade de } \\
\text { Crescimento }\end{array}$ & - & $\begin{array}{l}\text { Huang e Song (2006), Nakamura et. al. } \\
\text { (2007), Valle (2008), Iquiapaza, Amaral e } \\
\text { Araújo (2008), Bastos, Nakamura e Basso } \\
\text { (2009), Espinosa et al. (2012) }\end{array}$ & $+1-$ & Bastos et al. (2009) \\
\hline $\begin{array}{l}\text { Tamanho da } \\
\text { Empresa }\end{array}$ & + & $\begin{array}{l}\text { Barros e Silveira (2008), Medeiros e Daher } \\
\text { (2008), Espinosa et al. (2012), Forte, } \\
\text { Nakamura e Bastos (2013) }\end{array}$ & $+/-$ & Rajan e Zingales (1995) \\
\hline Risco do Negócio & - & $\begin{array}{l}\text { Favato e Rogers (2008), Valle e Albanez } \\
\text { (2012) }\end{array}$ & - & $\begin{array}{l}\text { Favato e Rogers (2008), Valle e } \\
\text { Albanez (2012) }\end{array}$ \\
\hline $\begin{array}{l}\text { Taxa de } \\
\text { crescimento do } \\
\text { PIB }\end{array}$ & \multicolumn{2}{|c|}{ Indefinido } & - & Bastos et al. (2009); Terra (2007); \\
\hline Taxa de Inflação & + & Frank e Goyal (2007) & Inde & \\
\hline
\end{tabular}

Essas relações dos determinantes com o endividamento permitirão a comparação dos resultados desta pesquisa com o previsto pelas teorias de estrutura de capital Tradeoff e Pecking Order, a fim de testar a validade das mesmas no cenário brasileiro e chinês.

\section{Análise dos Dados}

Para iniciar a análise dos dados foi utilizada a técnica estatística de regressão linear múltipla, que é a ferramenta analítica mais utilizada e versátil para avaliar relações de dependência entre variáveis (HAIR et al., 2005). Associado à análise de regressão, utilizou-se o modelo econométrico por dados em painel (Panel Data), que consiste na observação de um conjunto de unidades em séries temporais de corte transversal, isto é, observações de múltiplas empresas, nas quais cada empresa é observada em no mínimo dois períodos de tempo diferentes (STOCK \& WATSON, 2004). Dessa forma, essa ferramenta de regressão linear múltipla com dados em painel, que possibilitou avaliar a efetividade dos determinantes utilizados nesta pesquisa, pode ser representada pela fórmula geral a seguir:

$$
Y_{i t}=\alpha_{i}+\beta_{1} X_{1 i t}+\beta_{2} X_{2 i t}+\cdots+\beta_{k} X_{k i t}+\varepsilon_{i t}
$$

Onde:

$Y$ - variável dependente;

$X_{1}, X_{2}, \ldots, X_{k}$ - variáveis explicativas;

$\alpha$ - intercepto;

$\beta_{1}, \beta_{2}, \ldots, \beta_{k}$ - coeficientes da regressão;

$\varepsilon$ - termo de erro estocástico;

$i$ - representa a $i$-ésima empresa, para $i=1, \ldots, \mathrm{n}$;

$t$ - representa o $t$-ésimo período de tempo, para $t=1, \ldots, \mathrm{T}$;

$k$ - representa o $k$-ésimo coeficiente e a $k$-ésima variável. 
No entanto, para tornar esta fórmula operacional, ou seja, para ser possível estimar os dados em painel, dois são os modelos mais utilizados que podem realizar essa estimação. São eles: efeitos aleatórios e efeitos fixos. O primeiro modelo não reconhece a especificidade das empresas e nem dos períodos de tempo. Dessa forma, o modelo de efeitos aleatórios pode trabalhar com uma grande dimensão de dados, fazendo inferências a uma população a partir de uma amostra aleatória. Porém, esse modelo não seria viável para este estudo, visto que a pesquisa não utiliza uma população de grande dimensão e que a escolha do modelo depende, principalmente, do objetivo do estudo e da forma como os dados foram recolhidos. Portanto, para controlar os efeitos específicos de uma amostra ou fazer previsões sobre a mesma, o modelo de efeitos fixos possibilita estimações mais precisas dos coeficientes ao tratar as diferenças individuais sistematicamente (FREES, 2003).

Então, o modelo de efeitos fixos, que busca controlar as variáveis omitidas que variam entre indivíduos, mas segue constante ao longo do tempo, será utilizado neste estudo, conforme o resultado do teste de Hausman, que indica qual modelo econométrico é o mais apropriado. Assim, o termo de perturbação, $\varepsilon_{i t}$, pode ser decomposto em efeito específico da empresa, $n_{i}$, que varia de uma empresa para outra (cross-sectionally), mas não ao longo do tempo, e em 'perturbação restante', $u_{i t}$, que varia tanto entre as empresas quanto ao longo do tempo (capturando tudo que foi deixado de ser explicado por $Y_{i t}$ ) (FREES, 2003 \& BROOKS, 2008). Sendo assim, pode-se indicar que:

$$
\varepsilon_{i t}=n_{i}+u_{i t}
$$

Dessa forma, ao substituir o termo de perturbação, $\varepsilon_{i t}$, disposto na Equação 1, pelo seu desdobramento, tem-se que:

$$
Y_{i t}=\alpha_{i}+\beta_{1} X_{1 i t}+\beta_{2} X_{2 i t}+\cdots+\beta_{k} X_{k i t}+n_{i}+u_{i t}
$$

Além disso, conforme Stock e Watson (2004) e Greene (2012), há duas formas associadas aos dados em painel quanto à falta de observações. Em primeiro lugar, o painel balanceado (balanced panel), que inclui o mesmo número de observações para cada empresa e cada período de tempo, no qual os coeficientes de regressão não variam entre as empresas. Em segundo lugar, o painel desbalanceado (unbalanced panel), o qual se refere a um painel com falta de dados em no mínimo um período de tempo para pelo menos uma empresa - ou seja, quando há número de observações diferentes entre os dados ao longo do tempo, resultando em coeficientes de regressão variados entre as empresas. Assim, a partir desses conceitos, optou-se pelo painel desbalanceado, mais amplamente aplicável pela ausência de observações ou pela forma de registro dos dados, embora a maior parte da literatura econométrica seja focada no painel balanceado (FREES, 2003 \& GREENE, 2012). Portanto, ao considerar as variáveis utilizadas neste estudo, pode-se, a partir da Equação 3, criar a equação geral deste trabalho, Equação 4, a 
qual permitirá encontrar os resultados deste trabalho para relacioná-los com a teoria e fazer inferências.

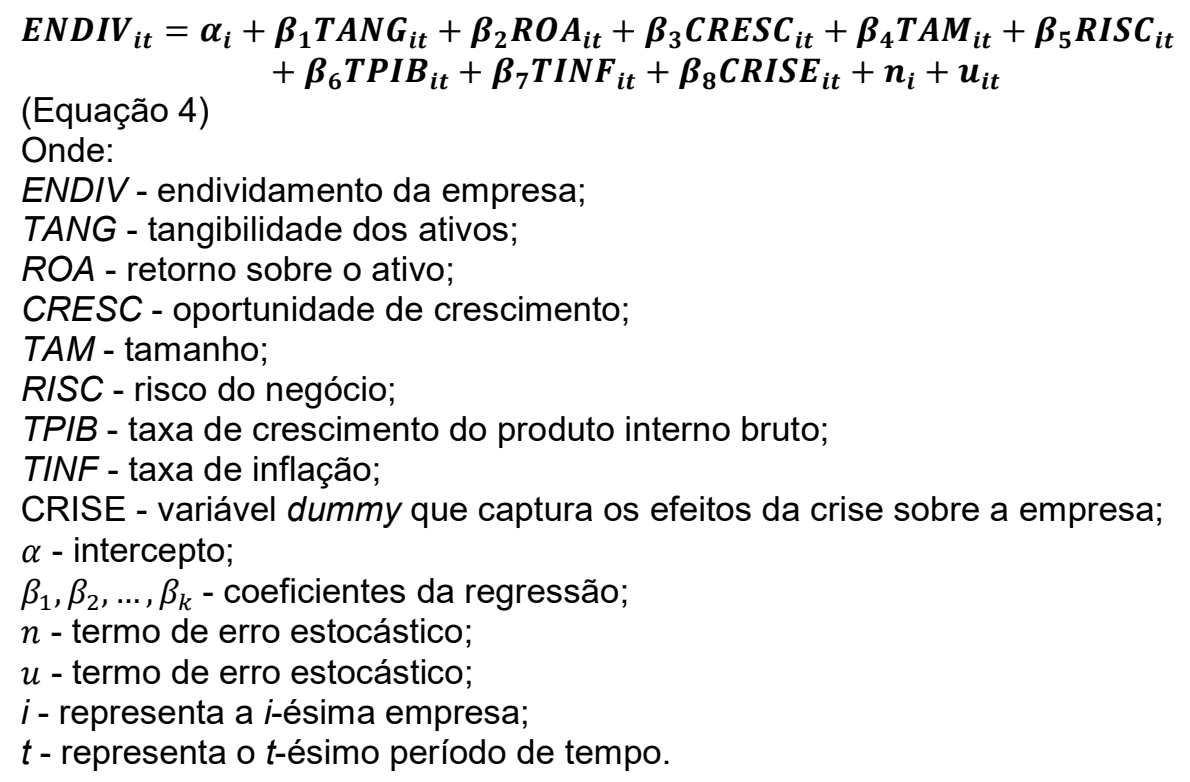

\section{RESULTADOS}

Este capítulo apresenta as análises de resultados desta pesquisa, as quais estão divididas em três etapas com o propósito de atingir os objetivos estabelecidos anteriormente. Portanto, iniciam-se com as análises das estatísticas descritivas e das correlações das variáveis estudadas. Depois disso, foi examinado se a teoria de Tradeoff ou a de Pecking Order sustentam as estruturas de capital das empresas brasileiras e chinesas. O seguinte passo será investigar a estrutura de capital das empresas do Brasil e da China nos períodos antes e depois da crise das hipotecas subprime, bem como apontar se houve alterações nas estratégias de financiamento dessas companhias.

\section{Análise das Estatísticas Descritivas}

Nesta primeira fase de análise, encontram-se as estatísticas descritivas (média, desvio padrão, mínimo e máximo) das variáveis estudadas, a fim de observar suas relações com a estrutura de capital à luz das teorias de Tradeoff e Pecking Order. Primeiramente, têm-se como destaque as médias das proxies de endividamento, elencados na seção 3.3.1 do método, no período de 2002 a 2011, nas empresas do Brasil e da China. Então, ao analisar a Gráfico 1 que contém esses valores, verifica-se nesse período um comportamento semelhante em ambos os países estudados. O nível de endividamento médio tendeu a diminuir, com uma queda acentuada no ano da crise de hipotecas, enquanto no ano de 2008 houve um aumento considerável. A partir do ano seguinte voltou a reduzir com um leve aumento em 2011. Contudo, os níveis de endividamento médio das empresas chinesas são maiores do que os das brasileiras. 


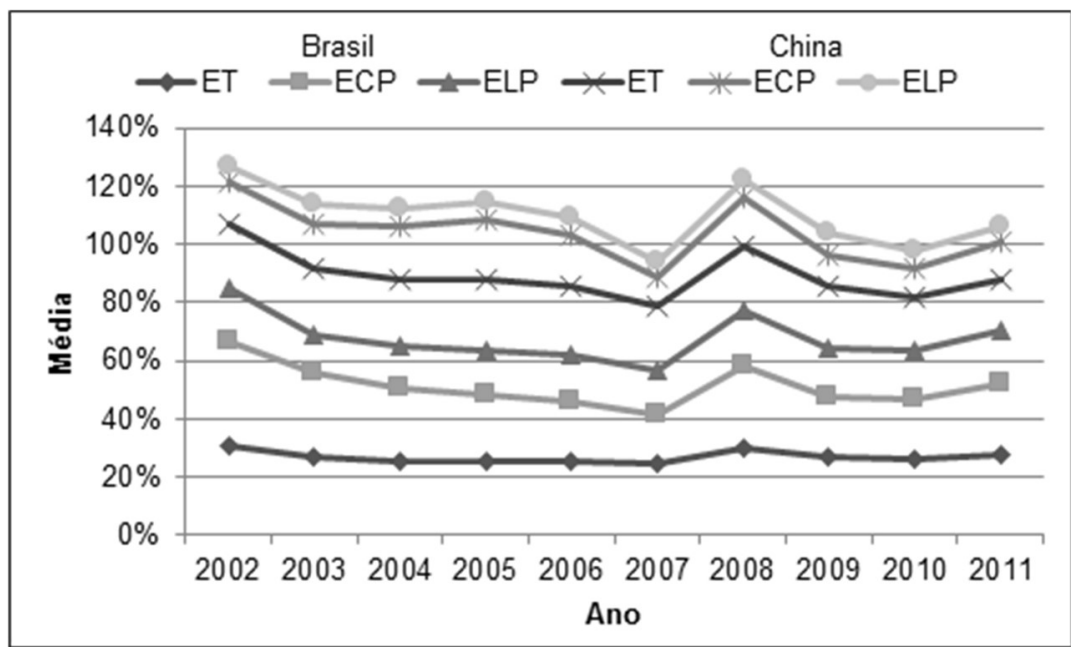

Gráfico 1: Endividamento médio no período (2002-2011) para o Brasil e China.

Nota: Endividamento Total $(\mathrm{ET}=$ passivo total $/$ ativo total), Endividamento de Curto Prazo $(\mathrm{ECP}=$ passivo circulante / ativo total), Endividamento de Longo Prazo (ELP = dívida total líquida / ativo total).

Nota-se no Gráfico 2 uma inclinação para cima da taxa de crescimento do PIB nos anos anteriores à crise subprime apesar de suas oscilações, ou seja, de uma maneira geral, foi registrado um crescimento econômico nos países antes da crise eclodir. Porém, nos anos seguintes, supostamente os países sentiram os efeitos da crise ao apresentarem níveis mais baixos da taxa de crescimento do PIB. Além disso, as oscilações do nível de endividamento dos dois países analisados podem estar relacionadas a essas mudanças da taxa de crescimento do PIB, principalmente quando se observa a relação inversa no ano da crise ao verificar uma alta do PIB (ver Figura 2) e baixa do nível de endividamento das empresas brasileiras e chinesas. No entanto, essa relação negativa não é um padrão nos anos analisados, o que aparentemente pode indicar a não influência do PIB no endividamento dessas empresas.

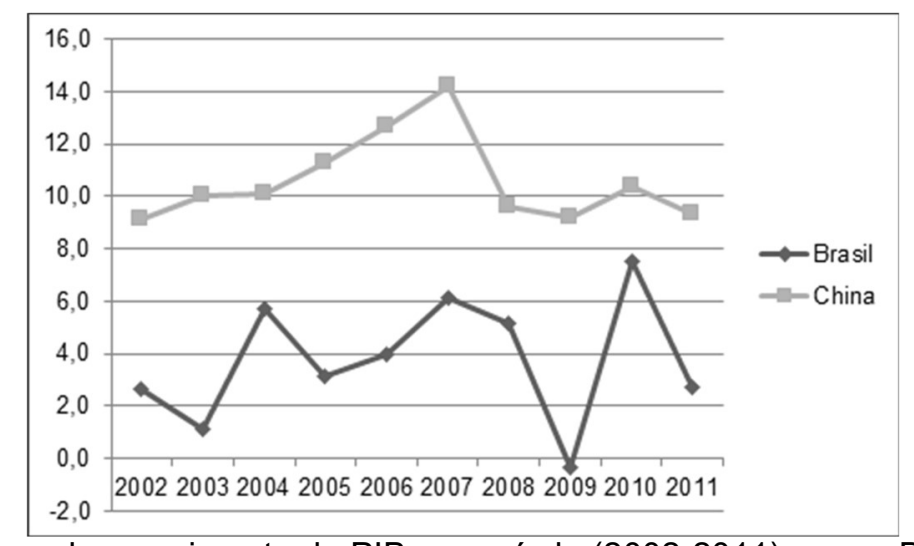

Gráfico 2: Taxa de crescimento do PIB no período (2002-2011) para o Brasil e China.

No Gráfico 3, verificamos que a taxa de inflação no Brasil apresentou tendência de queda antes da crise, ao passo que a China seguiu na direção oposta. No país asiático, o índice inflacionário cresceu no mesmo período analisado. No entanto, houve aumento da inflação no Brasil no ano posterior à crise subprime, seguido de um leve decréscimo em 2009 e de uma ascensão nos anos subsequentes. As estatísticas descritivas das variáveis em análise nas empresas do Brasil são dispostas na Tabela 2 e, nas empresas da China, na Tabela 3. 


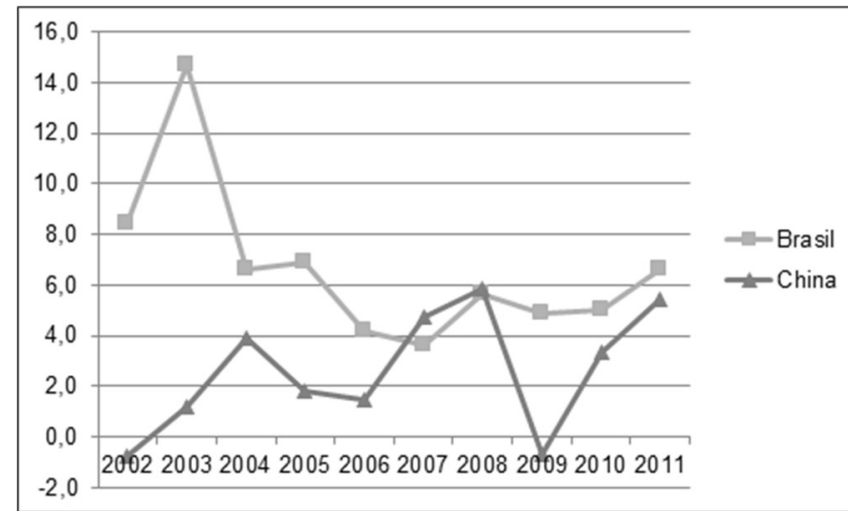

Gráfico 3: Taxa de inflação no período (2002-2011) para o Brasil e China.

Tabela 2: Estatística descritiva das variáveis das empresas brasileiras

As variáveis investigadas foram: endividamento total $(\mathrm{ET}=$ passivo total $/$ ativo total $)$, endividamento de curto prazo $(\mathrm{ECP}=$ passivo circulante / ativo total), endividamento de longo prazo (ELP = dívida total líquida / ativo total), tangibilidade (TANG), retorno sobre o ativo (ROA), oportunidade de crescimento (CRESC), tamanho (TAM), risco do negócio (RISC).

\begin{tabular}{|c|c|c|c|c|c|c|c|c|c|}
\hline Ano & Estatística & ET & ECP & ELP & TANG & ROA & CRESC & TAM & RISC \\
\hline \multirow{5}{*}{ ণิ } & $\mathrm{N}^{\circ}$ de Obs. & 73 & 73 & 73 & 67 & 73 & 73 & 73 & 72 \\
\hline & Média & 0,3059 & 0,3628 & 0,1794 & 0,7465 & 0,1120 & 0,8772 & 6,3320 & 0,0432 \\
\hline & Desvio Padrão & 0,1732 & 0,2084 & 0,1440 & 0,3334 & 0,0990 & 0,3506 & 1,6424 & 0,0336 \\
\hline & Mínimo & 0,0000 & 0,0000 & 0,0000 & 0,0426 & $-0,1020$ & 0,3358 & 3,5460 & 0,0046 \\
\hline & Máximo & 0,6555 & 0,8690 & 0,6191 & 1,6198 & 0,4209 & 2,3289 & 10,4441 & 0,2069 \\
\hline \multirow{5}{*}{ ஜి } & $\mathrm{N}^{\circ}$ de Obs. & 91 & 91 & 91 & 80 & 91 & 91 & 91 & 83 \\
\hline & Média & 0,2714 & 0,2885 & 0,1294 & 0,7492 & 0,0671 & 1,0095 & 6,0330 & 0,5362 \\
\hline & Desvio Padrão & 0,1778 & 0,2001 & 0,1301 & 0,4859 & 0,0946 & 0,4788 & 1,6824 & 2,9467 \\
\hline & Mínimo & 0,0000 & 0,0000 & 0,0000 & 0,0000 & $-0,3077$ & 0,0617 & 2,5429 & 0,0017 \\
\hline & Máximo & 0,9399 & 0,9685 & 0,6298 & 3,7588 & 0,3072 & 3,4596 & 10,6254 & 22,7616 \\
\hline \multirow{5}{*}{ ষ্ণ } & $\mathrm{N}^{\circ}$ de Obs. & 91 & 91 & 91 & 83 & 91 & 91 & 91 & 91 \\
\hline & Média & 0,2549 & 0,2505 & 0,1418 & 0,7094 & 0,0935 & 1,1853 & 6,3521 & 0,0433 \\
\hline & Desvio Padrão & 0,1559 & 0,1808 & 0,1225 & 0,3677 & 0,0739 & 0,6325 & 1,7228 & 0,0487 \\
\hline & Mínimo & 0,0000 & 0,0000 & 0,0000 & 0,0458 & 0,0283 & 0,1441 & 2,8918 & 0,0021 \\
\hline & Máximo & 0,8807 & 0,9330 & 0,6212 & 2,0487 & 0,2798 & 3,7738 & 10,9142 & 0,3827 \\
\hline \multirow{5}{*}{ 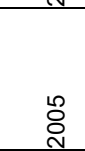 } & $\mathrm{N}^{\circ}$ de Obs. & 93 & 93 & 93 & 87 & 93 & 93 & 93 & 92 \\
\hline & Média & 0,2504 & 0,2337 & 0,1503 & 0,7117 & 0,0790 & 1,3036 & 6,4661 & 0,1098 \\
\hline & Desvio Padrão & 0,1493 & 0,1658 & 0,1316 & 0,3665 & 0,0918 & 0,7885 & 1,8035 & 0,3129 \\
\hline & Mínimo & 0,0000 & 0,0000 & 0,0000 & 0,0459 & $-0,3771$ & 0,2270 & 1,9993 & 0,0002 \\
\hline & Máximo & 0,5770 & 0,7120 & 0,5201 & 1,5599 & 0,3307 & 4,4816 & 11,2723 & 2,6973 \\
\hline \multirow{5}{*}{ 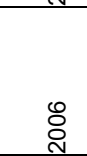 } & $\mathrm{N}^{\circ}$ de Obs. & 123 & 123 & 123 & 110 & 123 & 123 & 123 & 122 \\
\hline & Média & 0,2523 & 0,2050 & 0,1617 & 0,6623 & 0,0687 & 1,5246 & 6,4339 & 0,1919 \\
\hline & Desvio Padrão & 0,1596 & 0,1559 & 0,1383 & 0,3818 & 0,0837 & 0,9210 & 1,7833 & 1,2109 \\
\hline & Mínimo & 0,0000 & 0,0000 & 0,0000 & 0,0245 & $-0,1206$ & 0,1561 & 2,3570 & 0,0026 \\
\hline & Máximo & 0,5931 & 0,6221 & 0,5044 & 1,6252 & 0,4230 & 4,9511 & 11,4978 & 12,7163 \\
\hline \multirow{5}{*}{ 蜍 } & $\mathrm{N}^{\circ}$ de Obs. & 133 & 133 & 133 & 117 & 133 & 133 & 133 & 132 \\
\hline & Média & 0,2491 & 0,1674 & 0,1538 & 0,5815 & 0,0728 & 1,9479 & 6,6547 & 0,0351 \\
\hline & Desvio Padrão & 0,1570 & 0,1301 & 0,1337 & 0,3922 & 0,0826 & 1,2458 & 1,6152 & 0,0488 \\
\hline & Mínimo & 0,0000 & 0,0000 & 0,0000 & 0,0021 & $-0,0699$ & 0,5051 & 2,4287 & 0,0003 \\
\hline & Máximo & 0,5915 & 0,6602 & 0,5301 & 2,2097 & 0,3788 & 11,2337 & 11,7731 & 0,4280 \\
\hline \multirow{5}{*}{$\begin{array}{l}\infty \\
\stackrel{\sim}{N}\end{array}$} & $\mathrm{~N}^{\circ}$ de Obs. & 136 & 136 & 136 & 125 & 136 & 136 & 136 & 136 \\
\hline & Média & 0,3021 & 0,2810 & 0,1867 & 0,5316 & 0,1030 & 1,1948 & 6,5811 & 0,0432 \\
\hline & Desvio Padrão & 0,1867 & 0,1792 & 0,1606 & 0,3662 & 0,1181 & 0,5445 & 1,6519 & 0,0362 \\
\hline & Mínimo & 0,0000 & 0,0000 & 0,0000 & 0,0000 & $-0,3568$ & 0,5309 & 2,2046 & 0,0015 \\
\hline & Máximo & 0,7557 & 0,7780 & 0,7132 & 2,1745 & 0,5749 & 4,5207 & 11,7416 & 0,2459 \\
\hline \multirow{5}{*}{ ஜे } & $\mathrm{N}^{\circ}$ de Obs. & 178 & 178 & 178 & 162 & 178 & 178 & 178 & 178 \\
\hline & Média & 0,2677 & 0,2046 & 0,1708 & 0,6068 & 0,0644 & 1,5847 & 6,9086 & 0,0352 \\
\hline & Desvio Padrão & 0,1743 & 0,1459 & 0,1472 & 0,3849 & 0,1011 & 0,9902 & 1,7950 & 0,0369 \\
\hline & Mínimo & 0,0000 & 0,0000 & 0,0000 & 0,0000 & $-0,4080$ & 0,1831 & 1,4123 & 0,0005 \\
\hline & Máximo & 0,7605 & 0,5654 & 0,7605 & 2,1985 & 0,6342 & 7,7409 & 12,1968 & 0,3118 \\
\hline \multirow{5}{*}{$\stackrel{\circ}{\stackrel{2}{\alpha}}$} & $\mathrm{N}^{\circ}$ de Obs. & 189 & 189 & 189 & 167 & 188 & 189 & 189 & 184 \\
\hline & Média & 0,2578 & 0,2091 & 0,1691 & 0,4734 & 0,0765 & 1,6340 & 7,1226 & 0,3050 \\
\hline & Desvio Padrão & 0,1665 & 0,1509 & 0,1339 & 0,3606 & 0,1046 & 1,2080 & 1,7315 & 1,8557 \\
\hline & Mínimo & 0,0000 & 0,0000 & 0,0000 & 0,0000 & $-0,6143$ & 0,2302 & 2,0788 & 0,0003 \\
\hline & Máximo & 0,7143 & 0,5759 & 0,6517 & 2,2733 & 0,6162 & 7,5869 & 11,7694 & 19,2696 \\
\hline \multirow{5}{*}{$\bar{\kappa}$} & $\mathrm{N}^{\circ}$ de Obs. & 195 & 195 & 195 & 172 & 195 & 195 & 195 & 195 \\
\hline & Média & 0,2756 & 0,2465 & 0,1796 & 0,4562 & 0,0820 & 1,4194 & 7,1874 & 0,2328 \\
\hline & Desvio Padrão & 0,1767 & 0,1753 & 0,1392 & 0,3787 & 0,0999 & 1,0390 & 1,7144 & 1,1368 \\
\hline & Mínimo & 0,0000 & 0,0000 & 0,0000 & 0,0000 & $-0,1688$ & 0,3446 & 2,4500 & 0,0023 \\
\hline & Máximo & 0,7040 & 0,6369 & 0,5673 & 2,3613 & 0,5662 & 8,7430 & 12,6808 & 10,1144 \\
\hline
\end{tabular}

As estatísticas descritivas apresentam os fatores específicos (características das empresas) dos dois países analisados, em que se verificam pequenas oscilações nos valores médios de tangibilidade (TANG) dos dois países, mas, de modo geral, há uma tendência de diminuição da sua média no período estudado. Isso é perceptível ao observar a redução média de 
58,11\% em 2002 para 40,81\% em 2011 nas empresas chinesas - assim como nas brasileiras com $74,65 \%$ no primeiro ano e $45,62 \%$ no último. Essa queda na média da tangibilidade pode ter relação positiva com a redução da média do nível de endividamento das empresas de ambos os países confirmando a previsão da teoria de Tradeoff.

Tabela 3: Estatística descritiva das variáveis das empresas chinesas.

As variáveis investigadas foram: endividamento total $(E T=$ passivo total $/$ ativo total $)$, endividamento de curto prazo $(E C P=$ passivo circulante $/$ ativo total $)$, endividamento de longo prazo (ELP = dívida total líquida / ativo total), tangibilidade (TANG), retorno sobre o ativo (ROA), oportunidade de crescimento

\begin{tabular}{|c|c|c|c|c|c|c|c|c|c|}
\hline Ano & Estatística & ET & ECP & ELP & TANG & ROA & CRESC & TAM & RISC \\
\hline \multirow{5}{*}{ ָิ } & $\mathrm{N}^{\circ}$ de Obs. & 312 & 312 & 312 & 312 & 312 & 312 & 312 & 292 \\
\hline & Média & 0,2221 & 0,1463 & 0,0544 & 0,5811 & 0,0423 & 1,9615 & 5,7871 & 0,0573 \\
\hline & Desvio Padrão & 0,1529 & 0,1327 & 0,0832 & 0,3237 & 0,0633 & 1,1161 & 1,1547 & 0,3175 \\
\hline & Mínimo & 0,0000 & 0,0000 & 0,0000 & 0,0172 & $-0,2620$ & 0,2682 & 2,6491 & 0,0006 \\
\hline & Máximo & 0,6472 & 0,6953 & 0,5040 & 1,6520 & 0,2410 & 7,6675 & 10,9746 & 5,3984 \\
\hline \multirow{5}{*}{ ஜి } & $\mathrm{N}^{\circ}$ de Obs. & 370 & 370 & 370 & 370 & 370 & 370 & 370 & 364 \\
\hline & Média & 0,2298 & 0,1547 & 0,0663 & 0,5746 & 0,0518 & 1,7332 & 5,8238 & 0,0453 \\
\hline & Desvio Padrão & 0,1597 & 0,1254 & 0,0955 & 0,3161 & 0,0604 & 0,7490 & 1,2090 & 0,2338 \\
\hline & Mínimo & 0,0000 & 0,0000 & 0,0000 & 0,0173 & $-0,2920$ & 0,3710 & 2,5680 & 0,0004 \\
\hline & Máximo & 0,6708 & 0,6294 & 0,5050 & 1,7815 & 0,2355 & 5,6785 & 11,0698 & 4,3810 \\
\hline \multirow{5}{*}{ 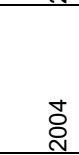 } & $\mathrm{N}^{\circ}$ de Obs. & 829 & 829 & 829 & 829 & 829 & 829 & 829 & 826 \\
\hline & Média & 0,2345 & 0,1774 & 0,0656 & 0,5373 & 0,0564 & 1,5476 & 5,5442 & 0,0254 \\
\hline & Desvio Padrão & 0,1598 & 0,1386 & 0,0975 & 0,2908 & 0,0632 & 0,6269 & 1,0917 & 0,0269 \\
\hline & Mínimo & 0,0000 & 0,0000 & 0,0000 & 0,0147 & $-0,6279$ & 0,2965 & 2,2944 & 0,0001 \\
\hline & Máximo & 0,7784 & 0,6743 & 0,4996 & 1,7837 & 0,3194 & 5,3295 & 11,2072 & 0,3210 \\
\hline \multirow{5}{*}{ ஜ) } & $\mathrm{N}^{\circ}$ de Obs. & 1222 & 1222 & 1222 & 1222 & 1222 & 1222 & 1222 & 1219 \\
\hline & Média & 0,2448 & 0,2063 & 0,0601 & 0,5861 & 0,0391 & 1,3462 & 5,4067 & 0,0269 \\
\hline & Desvio Padrão & 0,1620 & 0,1491 & 0,0943 & 0,2859 & 0,0679 & 0,5928 & 1,0894 & 0,0333 \\
\hline & Mínimo & 0,0000 & 0,0000 & 0,0000 & 0,0067 & $-0,3326$ & 0,2692 & 1,6327 & 0,0001 \\
\hline & Máximo & 0,9027 & 0,7042 & 0,6294 & 1,9168 & 0,3508 & 12,1155 & 11,4760 & 0,4522 \\
\hline \multirow{5}{*}{$\begin{array}{l}\text { ¿े } \\
\stackrel{N}{N}\end{array}$} & $\mathrm{~N}^{\circ}$ de Obs. & 1292 & 1292 & 1292 & 1292 & 1292 & 1292 & 1292 & 1291 \\
\hline & Média & 0,2402 & 0,1726 & 0,0615 & 0,5966 & 0,0457 & 1,7563 & 5,5250 & 0,0284 \\
\hline & Desvio Padrão & 0,1601 & 0,1384 & 0,0958 & 0,3007 & 0,0662 & 0,9646 & 1,1431 & 0,0411 \\
\hline & Mínimo & 0,0000 & 0,0000 & 0,0000 & 0,0003 & $-0,3749$ & 0,2687 & 2,4893 & 0,0003 \\
\hline & Máximo & 0,7736 & 0,6959 & 0,6055 & 2,2051 & 0,4136 & 9,4079 & 11,6234 & 0,7674 \\
\hline \multirow{5}{*}{ 옹 } & $\mathrm{N}^{\circ}$ de Obs. & 1376 & 1376 & 1376 & 1287 & 1376 & 1376 & 1376 & 1375 \\
\hline & Média & 0,2206 & 0,0939 & 0,0571 & 0,5119 & 0,0509 & 3,4581 & 5,7023 & 0,0282 \\
\hline & Desvio Padrão & 0,1529 & 0,0913 & 0,0910 & 0,2922 & 0,0745 & 2,3618 & 1,2198 & 0,0419 \\
\hline & Mínimo & 0,0000 & 0,0000 & 0,0000 & 0,0004 & $-0,6630$ & 0,3537 & 23,8189 & 0,0002 \\
\hline & Máximo & 0,7786 & 0,7572 & 0,5822 & 2,0347 & 0,4104 & 27,7068 & 11,8852 & 0,7961 \\
\hline \multirow{5}{*}{$\begin{array}{l}\infty \\
\stackrel{\sim}{0} \\
\end{array}$} & $\mathrm{~N}^{\circ}$ de Obs. & 1472 & 1472 & 1472 & 1469 & 1472 & 1472 & 1472 & 1470 \\
\hline & Média & 0,2224 & 0,1717 & 0,0602 & 0,5149 & 0,0398 & 2,0992 & 5,7932 & 0,0827 \\
\hline & Desvio Padrão & 0,1633 & 0,1481 & 0,1001 & 0,2984 & 0,0775 & 16,0803 & 1,2781 & 1,9788 \\
\hline & Mínimo & 0,0000 & 0,0000 & 0,0000 & 0,0000 & $-0,4578$ & 0,2756 & 0,0333 & 0,0001 \\
\hline & Máximo & 0,8287 & 0,7652 & 0,8006 & 2,7092 & 0,4981 & 617,2065 & 12,0723 & 75,8845 \\
\hline \multirow{5}{*}{ 옹 } & $\mathrm{N}^{\circ}$ de Obs. & 1569 & 1569 & 1569 & 1567 & 1569 & 1569 & 1569 & 1559 \\
\hline & Média & 0,2123 & 0,1096 & 0,0720 & 0,4869 & 0,0394 & 3,0603 & 5,8986 & 0,0473 \\
\hline & Desvio Padrão & 0,1710 & 0,1205 & 0,1104 & 0,3257 & 0,1012 & 3,3919 & 1,3294 & 0,5656 \\
\hline & Mínimo & 0,0000 & 0,0000 & 0,0000 & 0,0000 & $-2,6840$ & 0,3060 & 0,6036 & 0,0002 \\
\hline & Máximo & 0,7761 & 0,7161 & 0,6646 & 4,2893 & 0,5790 & 98,4293 & 12,2662 & 22,2104 \\
\hline \multirow{5}{*}{$\frac{\circ}{\circ}$} & $\mathrm{N}^{\circ}$ de Obs. & 1912 & 1912 & 1912 & 1912 & 1912 & 1912 & 1912 & 1883 \\
\hline & Média & 0,1827 & 0,0974 & 0,0623 & 0,4263 & 0,0507 & 3,2105 & 5,9845 & 0,0272 \\
\hline & Desvio Padrão & 0,1725 & 0,1233 & 0,1035 & 0,3361 & 0,0666 & 2,2887 & 1,2996 & 0,0656 \\
\hline & Mínimo & 0,0000 & 0,0000 & 0,0000 & $-0,4635$ & $-1,1116$ & 0,3424 & 1,9875 & 0,0002 \\
\hline & Máximo & 0,7778 & 0,7229 & 0,6294 & 6,4604 & 0,3199 & 27,1467 & 12,4324 & 2,4251 \\
\hline \multirow{5}{*}{$\underset{\sim}{\stackrel{\sim}{\sigma}}$} & $\mathrm{N}^{\circ}$ de Obs. & 2185 & 2185 & 2185 & 2182 & 2185 & 2185 & 2185 & 2184 \\
\hline & Média & 0,1801 & 0,1248 & 0,0564 & 0,4081 & 0,0501 & 2,1008 & 6,0882 & 0,0244 \\
\hline & Desvio Padrão & 0,1729 & 0,1448 & 0,0992 & 0,3189 & 0,0618 & 1,4144 & 1,3073 & 0,0628 \\
\hline & Mínimo & 0,0000 & 0,0000 & 0,0000 & 0,0000 & $-0,4347$ & 0,2770 & 1,8113 & 0,0002 \\
\hline & Máximo & 0,8774 & 0,7667 & 0,6450 & 6,3394 & 0,6797 & 26,2550 & 12,6261 & 2,4854 \\
\hline
\end{tabular}

Tabela 4: Matriz de correlação das variáveis das empresas brasileiras (2011).

Para o teste de correlação foram utilizadas as proxies de endividamento, medidas pelo endividamento total $(\mathrm{ET}=$ passivo total $/$ ativo total), endividamento de curto prazo (ECP = passivo circulante / ativo total), o endividamento de longo prazo (ELP = passivo não circulante / ativo total), a tangibilidade (TANG), o retorno sobre o ativo (ROA), a oportunidade de crescimento (CRESC), o tamanho (TAM), o risco do negócio (RISC). A caracterização operacional das variáveis de controle é apresentada na seção 3.2. * representam os valores significativos ao nível de $5 \%$.

\begin{tabular}{l|l|l|l|l|l|l|l|l}
\hline Variável & ET & ECP & ELP & TANG & ROA & CRESC & TAM & RISC \\
\hline ET & 1 & & & & & & & \\
\hline ECP & $0,8682^{*}$ & 1 & & & & & & \\
\hline ELP & $0,8407^{*}$ & $0,6851^{*}$ & 1 & & & & & \\
\hline TANG & 0,0422 & $0,1594^{*}$ & 0,0052 & 1 & & & & \\
\hline ROA & $-0,1055$ & $-0,2719^{*}$ & 0,0089 & $-0,0827$ & 1 & & & \\
\hline CRESC & $-0,1898^{*}$ & $-0,4101^{*}$ & $-0,1231$ & $-0,1699^{*}$ & $0,6459^{*}$ & 1 & & \\
\hline TAM & $0,2639^{*}$ & $0,1999^{*}$ & $0,4078^{*}$ & 0,0888 & $0,2337^{*}$ & 0,0152 & 1 & \\
\hline RISC & 0,0076 & 0,0266 & $-0,0219$ & $-0,0098$ & $-0,1062$ & $-0,0482$ & $-0,2941^{*}$ & 1 \\
\hline
\end{tabular}


Tabela 5: Matriz de correlação das variáveis das empresas chinesas (2011).

Para o teste de correlação foram utilizadas as proxies de endividamento, medidas pelo endividamento total $(\mathrm{ET}=$ passivo total $/$ ativo total), endividamento de curto prazo $(E C P=$ passivo circulante $/$ ativo total), o endividamento de longo prazo $(E L P=$ passivo não circulante / ativo total), a tangibilidade (TANG), o retorno sobre o ativo (ROA), a oportunidade de crescimento (CRESC), o tamanho (TAM), o risco do negócio (RISC). A caracterização operacional das variáveis de controle é apresentada na seção 3.2. * representam os valores significativos ao nível de $5 \%$.

\begin{tabular}{l|l|l|l|l|l|l|l|l}
\hline Variável & ET & ECP & ELP & TANG & ROA & CRESC & TAM & RISC \\
\hline ET & 1 & & & & & & & \\
\hline ECP & $0,9046^{*}$ & 1 & & & & & & \\
\hline ELP & $0,6936^{*}$ & $0,7217^{*}$ & 1 & & & & & \\
\hline TANG & $0,3624^{*}$ & $0,3545^{*}$ & $0,3332^{*}$ & 1 & & & & \\
\hline ROA & $-0,2224^{*}$ & $-0,2079^{*}$ & $-0,0968^{*}$ & $-0,1552^{*}$ & 1 & & & \\
\hline CRESC & $-0,2885^{*}$ & $-0,4003^{*}$ & $-0,2346^{*}$ & $-0,0482^{*}$ & $0,1089^{*}$ & 1 & & \\
\hline TAM & $0,4191^{*}$ & $0,5147^{*}$ & $0,4602^{*}$ & $0,1758^{*}$ & $0,1245^{*}$ & $-0,4199^{*}$ & 1 & \\
\hline RISC & $-0,0092$ & $-0,039$ & $-0,034$ & $0,3708^{*}$ & $-0,0493^{*}$ & $0,3050^{*}$ & $-0,0893^{*}$ & 1 \\
\hline
\end{tabular}

Já a média do retorno sobre o ativo (ROA) das empresas apresenta uma evolução diferente nos dois países. O retorno sobre o ativo (ROA) do caso brasileiro se relaciona positivamente com o nível de endividamento, haja vista que as médias das duas variáveis diminuem do primeiro ano para o último, $11,20 \%$ para $8,2 \%$ e $30,59 \%$ para $27,56 \%$, respectivamente, apoiando também a teoria de Tradeoff. Por sua vez, o retorno sobre o ativo (ROA) das empresas chinesas sofreu um aumento de 4,23\% em 2002 para 5,01\% em 2011, inversamente relacionado com diminuição do nível de endividamento médio que saiu de $22,21 \%$ em 2002 para 18,01\% no último ano, estando de acordo com a teoria de Pecking Order. Nas empresas do Brasil e da China o maior crescimento (CRESC) médio ocorreu no ano da crise de hipotecas com 194,79\% e 345,81\%, respectivamente, em consonância com o crescimento do PIB em 2007. No Brasil, o menor risco de negócio (RISC) médio foi observado no ano de 2007 em meio à crise financeira.

Em seguida, foi calculado o coeficiente de correlação de Pearson (r), a fim de identificar o comportamento das variáveis de controle e o nível de correlação com o endividamento. Assim, observou-se que no ano de 2011 (vide Tabela 3 e 5), a variável tamanho (TAM) apresenta, significativamente, um maior grau de correlação com o endividamento para as empresas de ambos os países estudados. Além disso, essa variável juntamente com a tangibilidade (TANG) é positivamente correlacionada com o endividamento. No caso desta última, há exceção em relação ao endividamento total (ET) e o endividamento de longo prazo (ELP) das empresas brasileiras. Por outro lado, o retorno sobre o ativo (ROA) e a oportunidade de crescimento (CRESC) se correlacionam negativamente, a não ser pelo ROA para com o ELP, no caso brasileiro. Por fim, nota-se o risco de negócio (RISC) como a única variável sem significância de correlação com nenhuma proxy do endividamento nos dois casos.

\section{Relações entre as Determinantes e a Estrutura de Capital}

Nesta seção, analisam-se os determinantes da estrutura de capital apresentadas no procedimento metodológico (item 3.2) e suas relações com essa estrutura, ao fazer um comparativo com o considerado pelas teorias de Tradeoff e Pecking Order por meio da análise de dados em painel. Com relação à crise (CRISE), verifica-se que essa variável apresenta uma 
relação inversa com o endividamento das empresas brasileiras, embora não tenha sido encontrada significância estatística. Já nas empresas chinesas observa-se que essa mesma relação tem significância. Logo, em períodos de crise as empresas de ambos os países não recorrem ao financiamento com fontes externas.

A tangibilidade (TANG) apresenta significância estatística na sua relação positiva com o grau de endividamento das empresas brasileiras - e negativa com o das empresas chinesas. primeiro cenário ocorre, de acordo com a teoria de Tradeoff, devido à possibilidade das empresas usarem sua maior quantidade de ativos tangíveis como garantia para novos empréstimos, aumentando seu endividamento. Por outro lado, o cenário chinês relaciona-se com a teoria de Pecking Order, segundo Medeiros e Daher (2008), na qual as empresas com mais ativos tangíveis têm propensão a emitir novas ações, ao invés de emitir dívida para se financiarem.

Já o retorno sobre o ativo (ROA) comportou-se como o esperado pela teoria de Pecking Order, ao encontrar sempre significativamente uma relação negativa com o nível de endividamento para as empresas de ambos os países estudados. Isso mostra que empresas mais rentável geram mais recursos internos, sem a necessidade de se endividar mais, diminuindo assim a captação de recursos externos. Essa relação negativa também foi encontrada por diversos autores nos seus trabalhos empíricos (VALLE, 2008; FUTEMA et al., 2009; VALLE \& ALBANEZ, 2012; CORREA et al., 2013; FORTE et al., 2013).

Quanto à oportunidade de crescimento (CRESC), percebe-se o sinal negativo na relação com a alavancagem das empresas dos dois países, o que é significante em todas as empresas analisadas do Brasil, mas, nas chinesas, apenas na segunda proxy do endividamento (ECP). O sinal encontrado confirma o previsto pelas duas teorias estudadas, o que pode ser explicado pelo maior fluxo de caixa gerado por esse crescimento e consequentemente a menor necessidade de captação de recursos externos. O Tamanho (TAM) mostrou-se significante para todas as proxies do endividamento dos dois países, exceto para o endividamento de curto prazo (ECP) das empresas brasileiras, que trazem uma relação positiva esperada ao considerar a menor probabilidade de falência das empresas de maior porte (maior diversificação). Tal fato aumenta a credibilidade delas para conseguir mais empréstimos, segundo as duas teorias estudadas. Não se confirma, assim, a relação negativa que a teoria de Peking Order também defende.

Já os resultados para o risco de negócio (RISC) apontam que quanto maior o risco das empresas chinesas maior será sua propensão a se endividarem mais (relação significativa) embora o endividamento de longo prazo dessas empresas tenha confirmado uma relação negativa, assim como em todas as proxies de endividamento das empresas brasileiras, porém não significativas estatisticamente. Dessa forma, verifica-se um desacordo das relações significativas com o preconizado pelas teorias de Tradeoff e Pecking Order.

A relação da variável macroeconômica taxa de crescimento do PIB (TPIB) apresentou significância apenas na relação com a média do endividamento total e de curto prazo das empresas chinesas, sendo a primeira uma relação positiva (não esperada) e a última uma relação 
inversa como esperado pela teoria de Pecking Order. Essa relação inversa também foi vista entre a taxa média de crescimento do PIB (TPIB) e a média de todas as proxies do endividamento das empresas brasileiras, porém sem apresentar significância estatística. Por fim, ao contrário da maioria dos trabalhos estudados, verifica-se nesta pesquisa a significância para a taxa de inflação (TINF) quanto a sua relação com o endividamento. Observa-se, então, que esta variável está em concordância com a teoria de Tradeoff no caso brasileiro, enquanto o contrário ocorre no caso chinês, em relação à proxy de endividamento de longo prazo (ELP).

Tabela 6: Painel desbalanceado com efeito fixo (2002-2011)

A variável dependente é o endividamento, sendo utilizado alternativamente o endividamento total (ET = passivo total / ativo total), endividamento de curto prazo (ECP = passivo circulante / ativo total), endividamento de longo prazo (ELP = dívida total líquida / ativo total). As variáveis de independentes são: tangibilidade (TANG), retorno sobre o ativo (ROA), oportunidade de crescimento (CRESC), tamanho (TAM), risco do negócio (RISC). A caracterização operacional das variáveis utilizadas é apresentada na seção 3.3. São apresentados os resultados dos parâmetros estimados (coeficientes), da estatística t e do p-valor, respectivamente. Os coeficientes foram estimados com painel desbalanceado com efeito fixo.

\begin{tabular}{|c|c|c|c|c|c|c|c|}
\hline \multirow{2}{*}{\multicolumn{2}{|c|}{$\begin{array}{l}\text { País } \\
\text { Variável } \\
\end{array}$}} & \multicolumn{3}{|l|}{ Brasil } & \multicolumn{3}{|l|}{ China } \\
\hline & & ALAV1 & ALAV2 & ALAV3 & ALAV1 & ALAV2 & ALAV3 \\
\hline \multirow{3}{*}{ CRISE } & $\beta$ & $-0,0121$ & \begin{tabular}{|l|}
$-0,0151$ \\
\end{tabular} & $-0,0112$ & $-0,0485$ & $-0,0955$ & $-0,0102$ \\
\hline & $t$ & $-1,3200$ & \begin{tabular}{|l|}
$-1,6200$ \\
\end{tabular} & $-1,4600$ & $-19,6400$ & $-44,4400$ & $-5,9300$ \\
\hline & $p$ & 0,1880 & 0,1050 & \begin{tabular}{|l|}
0,1450 \\
\end{tabular} & 0,0000 & 0,0000 & 0,0000 \\
\hline \multirow{3}{*}{ TANG } & $\beta$ & $-0,0385$ & \begin{tabular}{|l|}
$-0,0345$ \\
\end{tabular} & $-0,0075$ & 0,0523 & 0,0372 & 0,0144 \\
\hline & $t$ & $-2,6700$ & $-2,3700$ & $-0,6200$ & 8,8900 & 7,2700 & 3,5400 \\
\hline & $p$ & 0,0080 & 0,0180 & \begin{tabular}{|l|}
0,5370 \\
\end{tabular} & 0,0000 & 0,0000 & 0,0000 \\
\hline \multirow{3}{*}{ ROA } & $\beta$ & $-0,2482$ & \begin{tabular}{|l|}
$-0,1997$ \\
\end{tabular} & $-0,1660$ & $-0,3347$ & $-0,2821$ & $-0,0857$ \\
\hline & $t$ & $-5,1000$ & $-4,0600$ & $-4,0700$ & $-22,8300$ & $-22,1200$ & $-8,4300$ \\
\hline & $p$ & 0,0000 & 0,0000 & \begin{tabular}{|l|}
0,0000 \\
\end{tabular} & 0,0000 & 0,0000 & 0,0000 \\
\hline \multirow{3}{*}{ CRESC } & $\beta$ & $-0,0210$ & $-0,0715$ & $-0,0147$ & $-0,0010$ & $-0,0042$ & 0,0004 \\
\hline & $t$ & $-3,6900$ & $-12,4200$ & $-3,0700$ & $-1,8400$ & $-8,4800$ & 0,9100 \\
\hline & $p$ & 0,0000 & 0,0000 & 0,0020 & 0,0660 & 0,0000 & 0,3640 \\
\hline \multirow{3}{*}{ TAM } & $\beta$ & 0,0259 & 0,0138 & 0,0318 & 0,0689 & 0,0696 & 0,0399 \\
\hline & $t$ & 3,5500 & 1,8700 & 5,1900 & 34,9000 & 40,5400 & 29,1600 \\
\hline & $p$ & 0,0000 & 0,0620 & 0,0000 & 0,0000 & 0,0000 & 0,0000 \\
\hline \multirow{3}{*}{ RISC } & $\beta$ & $-0,0029$ & \begin{tabular}{|l|}
$-0,0004$ \\
\end{tabular} & $-0,0009$ & 0,0118 & 0,0370 & $-0,0004$ \\
\hline & $t$ & $-0,8000$ & \begin{tabular}{|l|}
$-0,1200$ \\
\end{tabular} & $-0,2900$ & 2,5200 & 9,1000 & $-0,1400$ \\
\hline & $p$ & 0,4240 & 0,9050 & 0,7750 & 0,0120 & 0,0000 & 0,8920 \\
\hline \multirow{3}{*}{ TPIB } & $\beta$ & $-0,0018$ & $-0,0001$ & $-0,0009$ & 0,0029 & $-0,0054$ & $-0,0003$ \\
\hline & $t$ & $-1,4700$ & $-0,1000$ & $-0,8700$ & 5,4900 & $-12,0500$ & $-0,7200$ \\
\hline & $p$ & 0,1420 & 0,9170 & 0,3870 & 0,0000 & 0,0000 & 0,4720 \\
\hline \multirow{3}{*}{ TINF } & $\beta$ & 0,0030 & 0,0077 & 0,0002 & 0,0003 & 0,0065 & $-0,0013$ \\
\hline & $t$ & 2,1300 & 5,3400 & 0,1600 & 0,7400 & 19,5100 & $-4,7200$ \\
\hline & $p$ & 0,0340 & 0,0000 & 0,8750 & 0,4570 & 0,0000 & 0,0000 \\
\hline \multirow{3}{*}{ Constante } & $\beta$ & 0,1651 & 0,2456 & \begin{tabular}{|l|}
0,0022 \\
\end{tabular} & $-0,1935$ & $-0,1597$ & $-0,1603$ \\
\hline & $t$ & 3,1100 & 4,5700 & 0,0500 & $-14,2700$ & $-13,5500$ & $-17,0500$ \\
\hline & $p$ & 0,0020 & 0,0000 & 0,9610 & 0,0000 & 0,0000 & 0,0000 \\
\hline \multicolumn{2}{|l|}{$\mathrm{N}^{\circ}$ de Obs, } & 1120 & 1120 & 1120 & 12366 & 12366 & 12366 \\
\hline \multicolumn{2}{|l|}{ Estatística F } & $\begin{array}{l}(8,922) \\
10,70\end{array}$ & $\begin{array}{l}(8,922) \\
37,24\end{array}$ & \begin{tabular}{|l|}
$(8,922)$ \\
9,37
\end{tabular} & $\begin{array}{l}(8,10123) \\
231,59\end{array}$ & $\begin{array}{l}(8,10123) \\
484,12\end{array}$ & \begin{tabular}{|l}
$(8,10123)$ \\
147,78
\end{tabular} \\
\hline \multicolumn{2}{|l|}{ Prob > F } & 0,0000 & 0,0000 & 0,0000 & 0,0000 & 0,0000 & 0,0000 \\
\hline \multicolumn{2}{|l|}{$\mathbf{R}^{2}$} & 0,0849 & 0,2442 & \begin{tabular}{|l|}
0,0752 \\
\end{tabular} & 0,1547 & 0,2767 & 0,1046 \\
\hline
\end{tabular}

\section{CONCLUSÕES}

Esta pesquisa buscou analisar as estruturas de capital das empresas do Brasil e da China, mediante a crise financeira mundial iniciada nos Estados Unidos em 2007. As empresas observadas foram aquelas listadas na BM\&FBOVESPA e na Shanghai Stock Exchange (SSE) com dados disponíveis no período de 2002 a 2011 no banco de dados Compustat. A partir dessas informações, elaborou-se uma estatística descritiva, cujos resultados indicam que 0 endividamento das empresas chinesas foi maior do que as do Brasil, mas em ambos os países houve influência da crise subprime, quando observado seu maior nível em 2008 entre as oscilações existentes no período analisado. Por sua vez, as evidências encontradas na correlação 
de Pearson revelam que a variável tamanho é a que melhor explica o endividamento das empresas analisadas, ao apresentar o valor de maior significância na relação com o endividamento - sendo essa uma relação positiva, o que confirma a teoria de Tradeoff. Já o risco de negócio foi a única variável que não apresentou relevância, pois seu sinal da relação com as proxies de endividamento total e de curto prazo das empresas do Brasil vai de encontro ao esperado pela teoria de Tradeoff e Pecking Order.

Por fim, outros destaques surgiram na análise em painel. A variável crise encontrou-se em uma relação inversa com o endividamento e com significância apenas nas empresas chinesas, ou seja, nessas empresas o fator crise influencia na determinação da estrutura de capital. Verificouse também a relevância dos fatores macroeconômicos taxa de crescimento do PIB e taxa de inflação nessa determinação. A primeira mostra o sinal inverso na relação com o endividamento de curto prazo das empresas chinesas assim como em todas as proxies de endividamento das empresas brasileiras, ou seja, quando há crescimento econômico, há um aumento de recursos internos das empresas, o que leva a reduzirem seus endividamentos, como preconizado pela teoria de Pecking Order (BASTOS et al., 2009). Já a segunda, mostra uma relação positiva com o endividamento, favorável a teoria de Tradeoff, exceto em relação a proxy de endividamento de longo prazo das empresas chinesas. Para Bastos et al. (2009), essa relação positiva ocorre devido à depreciação dos montantes nominais das dívidas, decorrente da crescente da inflação, o que torna a captação de recursos mais atrativa. Essa pesquisa, então, encontrou relevância dessa última variável, o que não ocorre na maioria dos trabalhos anteriores.

De maneira geral, concluiu-se que, na amostra estudada, há manifestação tanto da teoria de Tradeoff como da teoria de Pecking Order, sem que uma prevaleça sobre a outra, seja antes ou depois do período de crise estudado. Dessa forma, há um indicativo de que essas empresas, ao passar por períodos de crise semelhantes, deveriam atentar para que tipo de relação (positiva ou negativa) as variáveis clássicas e modernas estudadas mantém com o endividamento. Assim, em momentos de crise, sugere-se que as empresas ajustem a estrutura de capital.

De toda forma, o presente trabalho enfrenta limitações, entre as quais é destacado o tamanho da amostra e a ausência de certas variáveis que talvez fossem capazes de oferecer uma visão diferenciada sobre as estratégias de financiamento das empresas. Igualmente, considera-se que uma melhor modelagem econométrica, com técnicas distintas das utilizadas neste artigo, poderia aportar dados complementares de relevância para nossa análise. Finalmente, considerase que este trabalho sugere a necessidade de mais estudos sobre o tema, com tempo maior para análise. Também se vislumbra a possibilidade de lançar mão de outras ferramentas estatísticoeconométricas que possam ajudar na compreensão do comportamento das empresas. Em face dessas considerações, percebe-se que a compreensão das decisões da estrutura de capital demanda um tratamento mais aprofundado, o que certamente será realizado em análises futuras. 


\section{REFERÊNCIAS}

AKBAR, S.; REHMAN, S.; AND ORMROD, P.. The impact of recent financial shocks on the financing and investment policies of UK private firms. International Review of Financial Analysis, v.26, n.1, p.59-70, 2013.

ALBANEZ, T.; VALLE, M. R.. Impactos da assimetria de informação na estrutura de capital de empresas brasileiras abertas. Revista Contabilidade \& Finanças, v.20, n.51, p.6-27, 2009. DOI:

http://dx.doi.org/10.1590/S1519-70772009000300002

ANTONIOU, A.; GUNEY, Y.; PAUDYAL, K.. The Determinants of Capital Structure: Capital Market Oriented versus Bank Oriented Institutions. Journal of Financial and Quantitative Analysis, v.43, n.1, p.59-92, 2008. DOI: http://dx.doi.org/10.1017/S0022109000002751

BARROS, L. A. B. C.; SILVEIRA, A. M.. Excesso de confiança, otimismo gerencial e os determinantes da estrutura de capital. Revista Brasileira de Finanças, v.6, n.3, p.293-334, 2008.

BASTOS, D. D.; NAKAMURA, W. T.; BASSO, L. F. C. Determinantes da estrutura de capital das companhias abertas na América Latina: um estudo empírico considerando fatores macroeconômicos e institucionais. Revista de Administração Mackenzie, v.10, n.6, p.47-77,. 2009. DOI:

http://dx.doi.org/10.1590/S1678-69712009000600005

BERTONHA, J. F.. A estratégia nacional de defesa do Brasil e a dos outros BRICs em perspectiva comparada. Revista Brasileira de Política Internacional, v.56, n 2, p.112-130, 2013. DOI:

http://dx.doi.org/10.1590/S0034-73292013000200007

BROOKS, C.. Introductory Econometrics for Finance. 2 ed. New York: Cambridge University Press, 2008.

CERETTA, P. S.; VIEIRA, K. M.; FONSECA, J. L.; TRINDADE, L. L.. Determinantes da estrutura de capital: uma análise de dados em painel de empresas pertencentes ao Ibovespa no período de 1995 a 2007.

Revista de Gestão USP, v.16, n.4, p.29-43, 2009. DOI: http://dx.doi.org/10.5700/issn.21778736.rege.2009.36684

CORREA, C. A.; BASSO, L. F. C.; NAKAMURA, T. W.. A estrutura de capital das maiores empresas brasileiras: análise empírica das teorias de Pecking Order e Trade-off, usando panel data. Revista de Administração Mackenzie, v.14, n. 4, p.106-133, 2013. DOI: http://dx.doi.org/10.1590/S1678-

69712013000400005

CUNHA, M. A.; BICHARA, J. S.; MONSUETO, S. E.; LÉLIS, M. T. C.. Impactos da ascensão da China sobre a economia brasileira: comércio e convergência cíclica. Revista de Economia Contemporânea, v.15, n.3, p.406-440, 2011. DOI: http://dx.doi.org/10.1590/S1415-98482011000300002 DAVID, M.; NAKAMURA, W. T.; BASTOS, D. D.. Estudo dos modelos trade-off e peking order para as variáveis endividamento e payout em empresas brasileiras (2000-2006). Revista de Administração Mackenzie, v. 10, n. 6, p. 132-153, 2009. DOI: http://dx.doi.org/10.1590/S1678-69712009000600008 DURAND, D.. Cost of Debt and Equity Funds for Business: trends and problems in measurement. In: NBER BOOKS. Conference on Research in Business Finance. New York: National Bureau of Economic Research, 1952.

ESPINOSA, C. M.; MAQUIEIRA, C. V.; VIEITO, J. P.; GONZALEZ, M. A.. Capital structures in developing countries: the Latin American case. Investigación Económica, v.71, n.282, p.35-54, 2012.

FAVATO, V.; ROGERS, P.. Estrutura de Capital na América Latina e nos Estados Unidos: uma análise de seus determinantes e efeito dos sistemas de financiamento. Gestão \& Regionalidade, v.24, n.71, p.31-47, 2008.

FORTE, D.; BARROS, L. A.; NAKAMURA, W. T.. Determinants of the capital structure of small and medium sized brazilian enterprises. Brazilian Administration Review, v.10, n.3, p.347-369, 2013. DOI:

http://dx.doi.org/10.1590/S1807-76922013000300007

FRANK, M. Z.; GOYAL, V. K.. trade-off and pecking order theories of debt. New York: Social Science Research Network, 2007.

FREES, E. W.. Longitudinal and panel data: analysis and applications in the social sciences. Cambridge: Cambridge University Press, 2004. 
FUTEMA, M. S.; BASSO, L. F. C.; KAYO, E. K.. Estrutura de capital, dividendos e juros sobre o capital próprio: testes no Brasil. Revista Contabilidade \& Finanças, v.20, n.49, p.44-62, 2009. DOI:

http://dx.doi.org/10.1590/S1519-70772009000100004

GIL, A. C.. Como elaborar Projetos de Pesquisa. 5 ed. São Paulo: Atlas, 2010.

GREENE, W. H.. Econometric Analysis. 7 ed. Prentice Hall: New Jersey, 2012.

HAIR JUNIOR, J. F.; ANDERSON, R. E.; TATHAM, R. L.; BLACK, W. C.. Análise Multivariada de Dados. 5 ed. Porto Alegre: Bookman, 2005.

HUANG, S. G. H.; SONG, F. M.. The determinants of capital structure: evidence from China. China Economic Review, v.17, n.1, p.14-36, 2006. DOI: http://dx.doi.org/10.1016/i.chieco.2005.02.007

HUANG, X.; KABIR, R.; ZUBAIR, S.. The impact of financing on the investments of SMEs: evidence from the recent financial crisis. Australia: Melbourne, 2014.

IQUIAPAZA, R. A.; AMARAL, H. F.; ARAÚJO, M. S. B.. Testando as Previsões da Pecking Order Theory no financiamento das empresas brasileiras: uma nova metodologia. Revista de Administração Mackenzie. v. 9, n.3, p.157-183, 2008. DOI: http://dx.doi.org/10.1590/S1678-69712008000300008

JONG, A.; KABIR, R.; NGUYEN, T. T.. Capital structure around the world: The roles of firm- and countryspecific determinants. Journal of Banking \& Finance, v.32, n.9, p.1954-1969, 2008. DOI:

http://dx.doi.org/10.1016/.j.jbankfin.2007.12.034

KAYO, E. K.; KIMURA, H.. O efeito simultâneo do ano, da firma e do setor sobre a estrutura de capital: uma aplicação da análise multinível. In: ENCONTRO ANUAL DA ASSOCIAÇÃO NACIONAL DOS

PROGRAMAS DE PÓSGRADUAÇÃO EM ADMINISTRAÇÃO, 23. Anais. São Paulo: ANPAD, 2009.

LIMA, F. G.; ASSAF NETO, A.; PERERA, L. C. J.; DA SILVA, A. C.. The impacts in the capital structure of Brazilian companies during periods of crises. Journal of International Finance and Economics, v.11, n. 2, p.154-160, 2011.

MEDEIROS, O. R.; DAHER, C. E.. Testando teorias alternativas sobre estrutura de capital nas empresas brasileiras. Revista de Administração Contemporânea, v.12, n.1, p. 177-199, 2008. DOI:

http://dx.doi.org/10.1590/S1415-65552008000100009

MODIGLIANI, F.; MILLER, M.. The costs of capital, corporation finance, and the theory of investment. The American Economic Review, v.48, n.3, p.261-297, 1958.

MODIGLIANI, F.; MILLER, M.. Corporate income taxes and the cost of capital: a correction. American Economic Review, v.53, n.3, p.433-443, 1963.

MYERS, S. C.; MAJLUF, N. S.. Corporate financing and investment decisions when firms have information investors do not have. Journal of Financial Economics, v.13, n.2, p.187-221, 1984.

MYERS, S. C.. The capital structure puzzle. The Journal of Finance, v.39, n.3, p.575-592, 1984.

NAKAMURA, W. T.; MARTIN, D. M. L.; FORTE, D.; FILHO, A. F. C.; DA COSTA, A. C. F.; DO AMARAL, A. C.. Determinantes de estrutura de capital no mercado brasileiro - Análise de regressão com painel de dados no período de 1999-2003. Revista Contabilidade \& Finanças, v.18, n. 44, p.72-85, 2007. DOI:

http://dx.doi.org/10.1590/S1519-70772007000200007

RAJAN, R.; ZINGALES, L.. What do we know about capital structure? Some evidence from international data. The Journal of Finance, v. 50, n.5, p.1421-1460, 1995.

SILVA, C.. Uma breve análise do contágio da crise subprime americana para a economia brasileira. A Economia em Revista, v.18, n.1, p.123-137, Jul. 2010. DOI: http://dx.doi.org/10.4025/aere.v18i1.12942 STOCK, J.; WATSON, M.. Econometria. São Paulo: Pearson, 2004.

TERRA, P. R. S.. Estrutura de capital e fatores macroeconômicos na América Latina. Revista de Administração da USP, v. 42, n. 2, p. 192-204, Abr./Mai./Jun. 2007.

TITMAN, S.; WESSELS, R.. The determinants of capital structure choice. The Journal of Finance, v.43, n. 1, p.1-19, 1988. 
TRISTÃO, P. A.; DUTRA, V. R.. Fatores que influenciam na estrutura de capital das empresas listadas na Bovespa. Revista de Administração da Universidade Federal de Santa Maria, v.5, n.2, p.309-320, 2012. DOI: http://dx.doi.org/10.5902/198346596279

VALLE, M. R.. Juros Altos, Fontes de Financiamento e Estrutura de Capital: o Endividamento de Empresas Brasileiras no Período 1997-2006. In: ENCONTRO ANUAL DA ASSOCIAÇÃO NACIONAL DOS PROGRAMAS DE PÓSGRADUAÇÃO EM ADMINISTRAÇÃO, 22. Anais. Rio de Janeiro: ANPAD, 2008.

VALLE, M. R.; ALBANEZ, T.. Juros Altos, Fontes de Financiamento e Estrutura de Capital: O Endividamento de Empresas Brasileiras no Período 1997-2006. Revistas de Contabilidade e Organizações, v.6, n.16, p. 49-72, 2012. 